\title{
PENURUNAN KADAR ARSEN PADA SELADA KERITING (Lactuca sativa crispa) MENGGUNAKAN AIR PERASAN JERUK NIPIS (Citrus aurantifolia swingle)
}

Ika Agustina Windasari, Narwati, Rusmiati

\begin{abstract}
Lettuce is a fresh vegetable that is consumed directly. However, if it is not treated properly, it could have potential health impact on humans. One effort to reduce the content of arsenic with a natural chelating agent is lime juice. The purpose of this study is to analyze the decreasing of arsenic level on curly lettuce before and after immersion using lime juice.

This research is a pure experimental. The methods which used are organoleptic test and arsenic level examination which used is Atomic Absorption Spectrophotometer (SSA).

The result of qualified organoleptic test is the concentration of lime juice $25 \%$ and $50 \%$, while the unorganized test of organoleptic is $75 \%$ concentration. One Way ANOVA test showed $p<0,05$ so there were significant differences. It was concluded that lime juice can be used to reduce arsenic levels, to reduce arsenic and maintain the quality of curly lettuce can use $25 \%$ concentration of lime juice.

Keywords : Arsenic (As), Curly Lettuce, Lime juice
\end{abstract}

\section{A. PENDAHULUAN}

Sayuran merupakan makanan yang banyak mengandung vitamin, vitamin berfungsi sebagai zat pertumbuhan dan pemeliharaan jaringan yang penting untuk tubuh manusia. Sayuran dikonsumsi dengan dua cara yaitu setelah proses pemasakan dan tanpa proses pemasakan. Sayuran tanpa proses pemasakan dikonsumsi secara langsung atau segar yang biasa digunakan untuk lalapan, contohnya seperti sayuran selada. Selada adalah salah satu sayuran yang banyak mengandung vitamin $A$, vitamin B1 dan vitamin C. Sayuran segar yang langsung dikonsumsi khususnya selada jika tidak diolah dengan baik dan benar dapat berpotensi memberikan dampak kesehatan yaitu keracunan, iritasi usus, gangguan ginjal, gangguan hati, kelainan kromosom, anemia, diabetes, penyakit saraf, hipertensi serta menyebabkan efek karsinogenik (Zahra dkk, 2017).

Dampak kesehatan tersebut timbul karena terdapat kandungan logam berat pada sayuran yang melebihi batas standar yang telah ditetapkan sesuai SNI 7387 Tahun 2009 mengenai batas maksimum cemaran logam berat pada makanan. Logam berat yang berpotensi menyebabkan gangguan kesehatan tersebut yaitu arsen. Arsen dapat mengkontaminasi makanan seperti yang terjadi di Bangladesh dimana arsen ditemukan di dalam kandungan padi dan sayuran dengan konsentrasi tinggi. Sejak paparan logam beracun tersebut menjadi penyebab morbiditas yang tinggi di Bangladesh, sehingga semakin diakui secara global bahwa logam arsenik sangat berbahaya bagi kesehatan. Terutama bila arsen masuk dalam rantai makanan dengan konsentrasi tinggi (Khan, et al : 2010).

Tujuan penelitian ini menganalisis penurunan kadar arsen pada selada keriting sebelum dan sesudah perendaman menggunakan air perasan jeruk nipis.

\section{B. METODE PENELITIAN}

Jenis penelitian yang dilakukan adalah penelitian pra eksperimen dengan desain penilitian yang disebut 
One Group Prettest and Posttest Design. Populasi pada penelitian ini adalah selada keriting yang dijual di masyrakat, Sampel yang digunakan dalam penelitian ini adalah selada keriting yang diperoleh di Pasar daerah Surabaya. Teknik sampling yang digunakan yaitu Purposive sampling adalah teknik penentuan

\section{HASIL DAN PEMBAHASAN}

sampel dengan pertimbangan atau kriteria tertentu (Sujarweni, 2015). Kriteria yang dibutuhkan untuk uji yaitu selada yang diambil sebagai sampel adalah jenis selada keriting, berdaun segar warna hijau, daun selada keriting yang digunakan yaitu berdaun lebar, tidak menggulung dan teksturnya tebal.

\section{Hasil Uji Organoleptik}

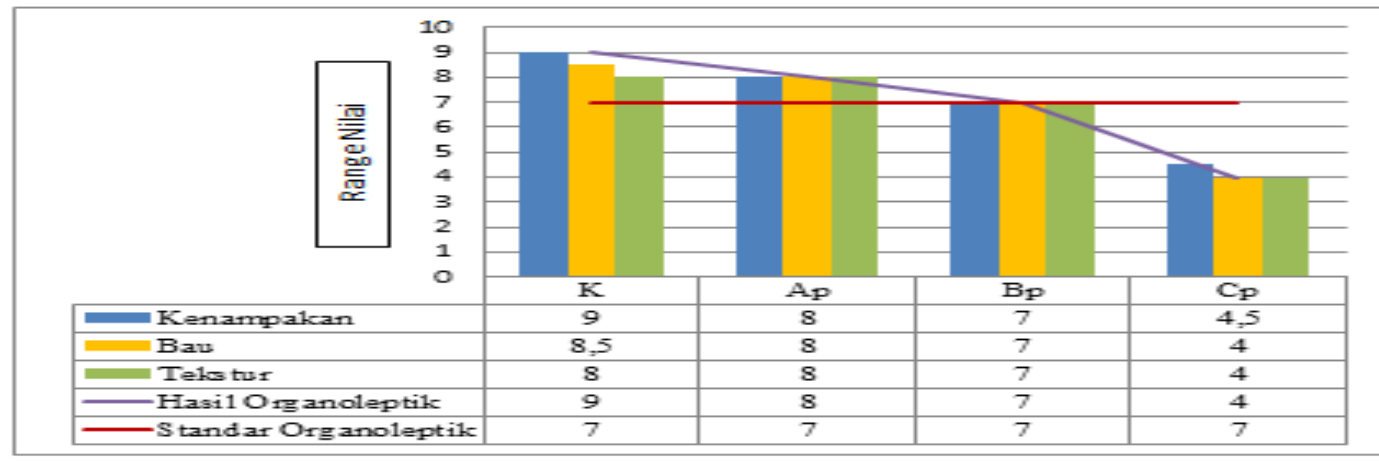

Gambar V.l Hasil Penilaian Sifat Sensori atau Uji Organoleptik Selada Keriting Sebelum Dan Sesudah Perlakuan

1. Selada Sebelum Perlakuan Kondisi selada keriting yang segar yaitu utuh, tidak layu, warna spesifik jenis selada keriting (hijau), cemerlang, bau sangat segar spesifik jenis selada keriting, tekstur daun kompak, padat dan tidak lembab. Kondisi kenampakan, bau dan tekstur tersebut dikarenakan selada keriting yang digunakan adalah sayuran yang berkualitas baik dan segar. Sayuran yang segar adalah sayuran yang tidak mengalami perubahan fisik maupun kimia serta dalam keadaan bersih (Hussain \& Ravi, 2017).

2. Selada Setelah Perlakuan

a. Kenampakan

Hasil dari kenampakan memiliki nilai rerata perlakuan $A_{p}$ 8, $B_{p} 7$, dan $C_{p} 4,5$. Perlakuan $A_{p}$ kenampakan tidak berubah atau sama seperti sebelum perlakuan yaitu warna utuh, rapi, warna spesifik jenis selada keriting (hijau), cemerlang. Berbeda dengan perlakuan $B_{p}$ dan $C_{p}$ yang mengalami perubahan kenampakan menjadi lebih layu dan warna hijau pada selada keriting berubah menjadi lebih tua dan kecoklatan. Menurut Fajar, Ratna \& Eko, (2014) reaksi penghitaman atau pencoklatan yang terjadi pada sayuran sebagai hasil dari degradasi klorofil, karena klorofil mudah terdegradasi terutama oleh pengaruh cahaya, suhu, $\mathrm{pH}$ dan oksigen. Menurut Couto (2016) media asam akan mempengaruhi logam inti dari klorofil dan terjadi pergantian oleh ion hidrogen, dengan konsekuen terjadi perubahan warna hijau asli menjadi hijau zaitun. Hal ini selaras dengan penelitian ini, faktor yang mempengaruhi perubahan warna daun selada keriting adalah $\mathrm{pH}$ 
dari larutan air perasan jeruk nipis yaitu $\mathrm{pH}$ asam dari variasi konsentrasi $25 \%$, 50\% dan $75 \%$ secara berturut-turut $3 ; 2,5$ dan 2. Kehadiran asam menyebabkan klorofil mengalami degradasi secara feofitin. Feofitin merupakan salah satu turunan klorofil yang terbentuk jika inti logam klorofil terlepas.Pengaruh asam yang mempunyai kandungan ion $\mathrm{OH}$ - akan mengikat ion logam magnesium yang ada dalam cincin makrosiklik klorofil, sehingga ion tersebut akan terlepas.

b. Bau

Hasil dari parameter bau memiliki nilai rerata perlakuan $A_{p}$ 8, $\mathrm{B}_{\mathrm{p}} 7$, dan $\mathrm{C}_{\mathrm{p}}$ 4.Pada perlakuan $A_{p}$ bau tidak berubah atau sama seperti sebelum perlakuan yaitu bau sangat segar spesifik jenis selada keriting. Berbeda dengan perlakuan $B_{p}$ dan $C_{p}$ yang mengalami perubahan pada bau. Bau pada kelompok $B_{p}$ dan $C_{p}$ cenderung berubah masam atau berbau asam lebih tajam. Bau asam tersebut berasal dari larutan jeruk nipis yang digunakan untuk perendaman. Larutan air perasan jeruk nipis tersebut mengandung asam sitrat kemudian saat perendaman larutan air perasan jeruk nipis masuk secara difusi kedalam jaringan sel pada selada keriting. Menurut Gaur, Lallan dan Susanta (2014) difusi adalah peristiwa perpindahan partikel atau molekul dari daerah konsentrasi tinggi ke daerah dengan konsentrasi rendah, sehingga dapat menyebar rata ke seluruh media. Kemudian mengakibatkan terperangkapnya asam sitrat yang larut air di dalam seluruh jaringan sel pada selada keriting, hal ini membuat $\mathrm{pH}$ selada keriting menurun selama setelah perendaman sehingga menimbulkan aroma atau bau asam pada selada keriting. Ketajaman bau asam atau bau masam dari jeruk nipis akan semakin kuat seiring dari pemberian konsentrasi yang tinggi.

c. Tekstur

Hasil dari parameter bau memiliki nilai rerata perlakuan $A_{p}$ 8, $\mathrm{B}_{\mathrm{p}}$ 7, dan $\mathrm{C}_{\mathrm{p}}$ 4. Pada perlakuan $A_{p}$ tekstur tidak berubah atau sama seperti sebelum perlakuan yaitu daun kompak, padat dan tidak lembab. Berbeda dengan perlakuan $B_{p}$ dan $C_{p}$ yang mengalami perubahan pada tekstur menjadi lebih lunak dan lembab.

Kandungan asam sitrat yang terdapat pada larutan air perasan jeruk nipis tersebut masuk kedalam sel-sel jaringan pada selada keriting dan membuat kadar air dalam selada keriting berkurang serta terjadi degradasi dinding sel. Setelah terjadi degradasi dinding sel maka kekuatan tekanan turgor berkurang. Tekanan turgor inilah yang berperan dalam kekerasan atau tekstur pada sayuran karena berperan dalam menekan isi sel terhadap dinding sel. Menurut Ernawati (2012) menurunnya mutu pada parameter kekerasan atau tekstur dari sayuran disebabkan karena hilangnya tekanan turgor dan degradasi dinding sel 


\section{Kadar Arsen (As) pada Selada Keriting Sebelum Perendaman dengan Air Perasan Jeruk Nipis}

Tabel 1.

\section{Kadar Arsen Pada Selada Keriting Sebelum Dilakukan Perendaman Air}

Perasan Jeruk Nipis - Tahun 2018

\begin{tabular}{|l|c|c|}
\hline No & $\begin{array}{c}\text { Kode } \\
\text { Sampel }\end{array}$ & $\begin{array}{c}\text { Kadar Arsen Pada } \\
\text { Selada Keriting } \\
\text { (mg/kg) }\end{array}$ \\
\hline 1. & $\mathrm{~K} 1$ & 0,19 \\
\hline 2 & $\mathrm{~K} 2$ & 0,21 \\
\hline 3 & $\mathrm{~K} 3$ & 0,18 \\
\hline 4 & $\mathrm{~K} 4$ & 0,17 \\
\hline 5 & $\mathrm{~K} 5$ & 0,20 \\
\hline 6. & $\mathrm{~K} 6$ & 0,20 \\
\hline \multicolumn{2}{|c|}{ Jumlah } & $\mathbf{1 , 1 5}$ \\
\hline \multicolumn{2}{|c|}{ Rerata } & $\mathbf{0 , 1 9 1}$ \\
\hline
\end{tabular}

Rerata kadar arsen pada selada keriting dengan nilai tertingi yaitu

$0,21 \mathrm{mg} / \mathrm{kg}$ dan kadar arsen terendah yaitu $0,17 \mathrm{mg} / \mathrm{kg}$, maka

rerata kadar arsen pada selada keriting kelompok kontrol atau sebelum perlakuan adalah 0,191 $\mathrm{mg} / \mathrm{kg}$. Kadar arsen tersebut masih dibawah nilai ambang batas yang diperbolehkan oleh SNI nomor 7387 tentang batas maksimum cemaran logam berat dalam pangan tahun 2009 yaitu sebesar $0,25 \mathrm{mg} / \mathrm{kg}$.

Tanaman pangan seperti sayuran dan sereal menjadi jalan dimana arsen dapat memasuki rantai makanan, hal itu bisa terjadi terutama karena jalur lingkungan dimana tanaman tersebut dibudidayakan atau ditanam seperti tanah dan air irigasi yang tercemar atau mengandung arsen (S. Samrana dkk, 2017). Masuknya arsen pada tanaman dapat karena kegiatan manusia yaitu seperti penggunaan pestisida atau herbisida yang mengandung arsen contohnya arsen putih yang digunakan untuk membasmi rumput liar dan kontribusi dari penggunaan berbagai jenis pupuk seperti pupuk $\mathrm{N}$, pupuk $\mathrm{P}$, pupuk kandang dan kompos (Purbalisa dkk, 2018). Selain itu translokasi komponen arsenik oleh tumbuhan tergantung pada ketersediaan alami total yang ada di dalam tanah. Pada tumbuhan, akumulasi kadar arsen tertinggi ada di akar dan akumulasi terendah terdapat di buah (akar>daun>buah) (McBride et al, 2015).

Arsenik adalah senyawa yang sangat beracun untuk seluruh organisme. Mengkonsumsi makanan terutama sayuran tanpa pengolahan dan mengandung arsen dapat membahayakan kesehatan tubuh manusia. Arsen merupakan bahan beracun yang sangat berbahaya jika tertelan ke dalam saluran cerna dan dalam jumlah tertentu dapat mengakibatkan keracunan akut serta keracunan kronis. Arsenik yang masuk kedalam saluran cerna khususnya arsen golongan anorganik yaitu arsen yang sangat beracun mempunyai 
sifat yang mudah diserap oleh saluran cerna kemudian terbawa dan diangkut oleh darah kemudian diedarkan keseluruh bagian tubuh. Dari keseluruhan total arsenik, yang dapat diserap oleh tubuh sebesar $90 \%$. Kemudian dalam beberapa hari tubuh mampu mengeskresi total arsenik sebesar $20-25 \%$ melalui urin (Motarjemi dkk, 2014 : 343).

\section{Perbedaan Penurunan Kadar Arsen pada Selada Keriting Sebelum dan Sesudah Perendaman Air Perasan Jeruk Nipis}

Tabel 2.

Penurunan Kadar Arsen Pada Selada Keriting Sebelum Dan Sesudah Perendaman Dengan Air Perasan Jeruk Nipis- Tahun 2018

\begin{tabular}{ccccccc}
\hline Kode & $\begin{array}{c}\text { Waktu } \\
\text { (menit) }\end{array}$ & $\begin{array}{c}\text { Nilai } \\
\text { Organoleptik }\end{array}$ & $\begin{array}{c}\text { Arsen pada Selada } \\
\text { Keriting } \\
\text { (mg/kg) }\end{array}$ & $\begin{array}{c}\text { Penurunan } \\
\text { Kadar } \\
\text { Arsen } \\
\text { (mg/kg) }\end{array}$ & $\begin{array}{c}\text { Penurunan } \\
\text { Kadar } \\
\text { Arsen (\%) }\end{array}$ \\
\cline { 5 - 6 } & & 8 & 0,191 & 0,12 & 0,071 & 37,17 \\
\hline $\mathrm{Ap}$ & 15 & & Sebelum & Sesudah & \\
\hline $\mathrm{Bp}$ & 15 & 7 & 0,191 & 0,088 & 0,103 & 53,93 \\
\hline $\mathrm{Cp}$ & 15 & 4 & 0,191 & 0,013 & 0,181 & 94,76 \\
\hline
\end{tabular}

Maka dari hasil tersebut dapat dilihat penurunan kadar arsen paling tinggi terdapat pada kelompok $\mathrm{Cp}$ dengan konsentrasi air perasan jeruk nipis $75 \%$ karena konsentrasi air perasan jeruk nipis yang lebih banyak dari air mempengaruhi jumlah kandungan asam sitrat serta kekuatan pengikatan asam sitrat terhadap logam berat Arsen pada selada keriting.Asam sitrat dapat digunakan sebagai pengkhelat pada logam karena memiliki empat elektron bebas yaitu pada gugus karboksil yang dapat diberikan pada ion logam kemudian dapat berikatan dan membentuk ligan yang bersifat larut dalam air. Proses pengikatan logam merupakan suatu proses kompleks dari ion logam dengan sekuestran. Secara umum proses pengikatan tersebut dapat dituliskan sebagai berikut: $L+S \rightarrow L S$, $L$ diibaratkan sebagai ion logam, sedangkan $S$ merupakan sekuestran, dan LS lambang dari kompleks ligan yang terbentuk (Saputri \& Rachmadiarti, 2015).
Maka dalam penelitian ini pada perendaman selada keriting yang dilakukan menggunakan air perasan jeruk nipis terjadi ikatan antara ion logam arsen dan asam sitrat. Berikut reaksi kimia antara arsen anorganik $\left(\mathrm{As}^{3+}\right)$ dengan asam sitrat:

$$
\begin{aligned}
& 2 \mathrm{C}_{6} \mathrm{H}_{8} \mathrm{O}_{7}+2 \mathrm{As} \rightarrow 2 \mathrm{C}_{6} \mathrm{H}_{5} \mathrm{O}_{7} \mathrm{As}+ \\
& 3 \mathrm{H}_{2}
\end{aligned}
$$

Menurut Herawati \& Soedaryo (2017) Dari struktur kimia diatas diketahui bahwa asam sitrat mampu mengikat ion logam karena asam organik (asam sitrat) memiliki gugus fungsional $-\mathrm{COOH}$, kemudian $(-\mathrm{COOH})$ yang terikat pada makromolekuler (asam sitrat) akan terurai beriringan dengan perubahan $\mathrm{pH}$ asam dan membentuk muatan negatif yang menyebabkan gugus fungsional tersebut bersifat "tertukar ion" (menjadi aktif). Atom hidrogen $(\mathrm{H})$ pada gugus karboksil $(-\mathrm{COOH})$ dapat dilepaskan sebagai ion $\mathrm{H}^{+}$ (proton) atau deprotonasi. Gugus $(-\mathrm{COOH})$ dapat mengalami 
deprotonasi pada $\mathrm{pH}$ yang relatif tinggi terutama karena asam adalah spesi pendonor $\mathrm{H}^{+}$, dengan pengaruh $\mathrm{pH}$ ini dapat mempunyai peluang membentuk ikatan kompleks dengan logam Arsen.

$\mathrm{pH}$ yang didapatkan pada masing-masing variasi konsentrasi $25 \%, \quad 50 \%$ dan $75 \%$ secara berurutan adalah 3 ; 2,5 dan 2, semakin tinggi konsentrasi semakin tinggi pula kandungan asam sitrat hal itu mempengaruhi $\mathrm{pH}$ pada larutan. Sehingga larutan yang berkonsentrasi tinggi dengan $\mathrm{pH}$ rendah adalah yang paling mudah melarutkan kandungan Logam berat Arsen pada selada keriting.

\section{Perbedaan Penurunan Kadar Arsen pada Selada Keriting Sebelum dan Sesudah Perendaman Air Perasan Jeruk Nipis}

Tabel 3.

\begin{tabular}{llllll}
\multicolumn{6}{c}{ Uji One Way Anova Kadar Arsen (As) Sesudah Dan Sebelum } \\
Perlakuan Perendaman Dengan Air Perasan Jeruk Nipis-Tahun 2018 \\
\hline Keterangan & $\begin{array}{c}\text { Sum of } \\
\text { Squares }\end{array}$ & df & $\begin{array}{c}\text { Mean } \\
\text { Square }\end{array}$ & F & Sig. \\
& 0,098 & 3 & 0,033 & 243,045 & 0,000 \\
\hline Between & 0,003 & 20 & 0,000 & & \\
\hline Within Groups & 0,101 & 23 & & & \\
\hline Total & 0,101 & &
\end{tabular}

Sumber : Data Primer

Berdasarkan hasil uji One Way ANOVA diperoleh nilai $\mathrm{P}$ sebesar 0,00 yang artinya $P<0,05(\alpha)$ maka terdapat perbedaan yang significant antara konsentrasi air perasan jeruk nipis dan waktu perendaman terhadap penurunan kadar arsen (As) pada selada keriting, sehingga terjadi penurunan kadar arsen (As) pada selada keriting sesudah perlakuan yaitu perendaman air perasan jeruk nipis dengan variasi konsentrasi $25 \%$, $50 \%$ dan $75 \%$ dan waktu perendaman selama 15 menit.

Terjadinya perbedaan penurunan kadar arsen pada selada keriting disebabkan karena adanya variasi konsentrasi air perasan jeruk nipis yang digunakan untuk merendam selada keriting. Menurut Silvia Nurvita, Nurjazuli, Nikie Astorina Yunita D (2015)bahwa kemampuan air perasan jeruk nipis dalam mereduksi kandungan logam berat yaitu semakin tinggi konsentrasi air perasan jeruk nipis yang digunakan maka akan semakin tinggi daya reduksinya. Hal itu terjadi karena air perasan jeruk nipis mengandung asam sitrat yang dapat mengikat logam.

Selain itu menurut James, Colin \& Heler (2008) proses difusi dipengaruhi oleh beberapa faktor yaitu konsentrasi, area permukaan, ketebalan bahan, jarak, temperatur dan tekanan. Pada penelitian ini perbedaan penurunan kadar arsen terjadi juga karena proses difusi yang berbeda, difusi larutan jeruk nipis akan semakin cepat pada kelompok perlakuan $\mathrm{Cp}$ dengan konsentrasi $75 \%$ karena adanya faktor konsentrasi yang tinggi serta bahan atau produk yang tipis (daun selada keriting) membuat larutan mudah untuk masuk dan menyebar. Menurut Herawati \& Soedoyo (2017) semakin tinggi konsentrasi suatu larutan, semakin cepat larutan tersebut untuk bereaksi dengan senyawa lain, dibuktikan pada penelitian ini 
karena jumlah konsentrasi asam sitrat yang tinggi memudahkan terbentuknya ikatan ligan antara asam sitrat dengan logam berat Arsen secara merata. Maka pada penelitian ini membuktikan bahwa potensi pada asam sitrat yang terdapat pada air perasan jeruk nipis mampu untuk menurunkan ion logam berat Arsen pada selada keriting.

\section{KESIMPULAN}

1 Hasil organoleptik selada keriting yang memenuhi syarat organoleptik adalah kelompok Ap (konsentrasi 25\%), kelompok Bp (konsentrasi $50 \%$ ) dan tidak memenuhi syarat kelompok Cp (konsentrasi 75\%).

2 Terdapat perbedaan penurunan kadar arsen (As) sebelum dan sesudah perlakuan perendaman menngunakan air perasan jeruk nipis dengan variasi konsentrasi 25\%, 50\% dan $75 \%$. Penurunan kadar arsen terbesar pada perlakuan perendaman konsentrasi air perasan jeruk nipis $75 \%$ ratarata penurunan adalah 0,181 $\mathrm{mg} / \mathrm{kg}$ dengan persentase penurunan sebesar $94,76 \%$, namun jika ditinjau dengan hasil uji organoleptik pada perlakuan ini menyebabkan terjadinya penurunan mutu yaitu perubahan kenampakan, bau dan tekstur.

\section{E. SARAN}

\section{Bagi Masyarakat}

a. Air perasan jeruk nipis dapat digunakan sebagai pengolahan awal perendaman untuk sayuran segar khususnya selada keriting yang dikonsumsi karena kandungan asam sitrat dalam air perasan jeruk nipis dapat menurunkan kadar logam berat arsen. Untuk menjaga mutu selada dan dapat digunakan untuk menurunkan logam berat Arsen maka menggunakan konsentrasi air perasan jeruk nipis 25\%.

\section{Bagi Penelitian Lain}

a. Dapat dilakukan penelitian mengenai perubahan kandungan gizi pada selada keriting sesudah perendaman dengan air perasan jeruk nipis.

b. Dapat dilakukan penelitian yang sama dengan perbedaan variasi waktu dalam penurunan kadar arsen menggunakan air perasan jeruk nipis.

c. Dapat dilakukan penelitian menggunakan bahan alami yang lain yang mengandung asam alami seperti belimbing wuluh atau air kelapa untuk penurunan kadar arsen pada makanan.

\section{F. DAFTAR PUSTAKA}

Couto, do Efimovna Cristina. 2016. Chlorophyll and Green Color Stabilization on Vegetable Homogenates.

Universidade de Lisboa. 8 Juli 2018.

Ernawati. 2012. Pengaruh Suhu Dan Lama Perendaman Blansir Terhadap Mutu Selada Kepala (Lactuca Sativa L.) Terolah Minimal Selama Penyimpanan. IPB.

Fajar, Ahmad, Ratna Ibrahim dan Eko Nurcahya Dewi.2014.Stabilitas 
Ekstrak Kasar Pigmen Klorofil, Beta Karoten, Dan Caulerpin Alga Hijau (Caulerpa Racemosa) Pada Suhu Penyimpanan Yang Berbeda. Jurnal Pengolahan dan Bioteknologi Hasil Perikanan Volume 3, Nomor 1 : 1-10. 1 Juli 2018.

Gaur, Ruchi, Lallan Mishra and Susanta K. Sen Gupta, 2014. Modelling and Simulation of Diffusive Processes. India.

Herawati, Dheasy \& Soedaryo, 2017. Pengaruh Perendaman Kerang Darah (Anadara Granosa) Dengan Perasan Jeruk Nipis Terhadap Kadar Merkuri $(\mathrm{Hg})$ Dan Kadmium (Cd). Jurnal SainHealth Vol. 1 No. 1. Sidoarjo. https://media.neliti.com/me dia/publications/231127pengaruh-perendamankerang-darah-anadara3c2560d1.pdf . 28 Juni 2018.

Hussain, Malik Altaf and Ravi Gooneratne. 2017. Understanding the Fresh Produce Safety Challenges. Vol. 6 (23). 20 Juni 2018

Khan, Shafiqul Islam, A.K. Mottashir Ahmed, Mohammad Yunus, Mahfuzar Rahman, Samar Kumar Hore, Marie Vahter, and M.A. Wahed, 2010. Arsenic and Cadmium in Food-chain in Bangladesh-An

Exploratory Study. J Health
Popul Nutr. 28(6) : 578584.

James, Joyce, Colin Baker and Helen Swain, 2008. Prinsip-Prinsip Sains untuk Keperawatan (Indonesian Edition). Jakarta, Erlangga : 28.

Nurvita, Sivia, Nurjazuli, \& Nikie Astorina Yunita D, 2015. Pengaruh Variasi Konsentrasi Air Jeruk Nipis (Citrus Aurantifolia) Dalam Menurunkan Kadar Kadmium (Cd) Pada Daging Kerang Darah (Anadara Granosa).Vol. 3 No. $\quad 3 . \quad$ Semarang. https://media.neliti.com/me dia/publications/18664-IDpengaruh-variasikonsentrasi-air-jeruk-nipiscitrus-aurantifolia-dalammenurunka.pdf. 7 Januari 2018.

McBride, Murray B.,Hannah A. Shayler, Jonathan $M$. Russell-Anelli, Henry M. Spliethoff, Lydia G. Marquez-Bravo,2015. Arsenic and Lead Uptake by Vegetable Crops Grown on an Old Orchard Site Amended with Compost.Water, Air, \& Soil Pollution. New York. http://cwmi.css.cornell.edu/ Arsenic-Lead-UptakeMcBride.pdf. 7 Januari 2018.

Motarjemi, Yasmine, Gerald Moy and Ewen Todd, 2014. Encyclopedia of Food Safety. London, Elsevier : 343.

Purbalisa, Wahyu, Anik Hidayah dan Sukarjo, 2018. Baku Mutu Arsen 
Pada Tanah Inceptisol GroboganDengan

Tanaman Indikator Padi. Jurnal Tanah dan Sumber daya Lahan. (5) No.1 : 621 627.

jtsl.ub.ac.id/index.php/itsl/a rticle/download/179/pdf . 10 Januari 2018.

Saputri, R., Rachmadiarti. F dan Raharjo, 2015. Penurunan Logam Berat Timbal $(\mathrm{Pb})$ Ikan Nila (Oreochromis nilotica) Kali Surabaya Menggunakan Filtrat Jeruk Siam (Citrus nobilis). Skripsi Jurusan Biologi Universitas.

SNI 7387 Tahun 2009 Tentang Batas Maksimum Cemaran
Logam Berat pada Makanan.

Sujarweni, Wiratna, 2015. Statistik Untuk Kesehatan. Yogyakarta, Gava Media : 21.

Zahra, Naseem, Imran Kalim , Minahil Mahmood and Nageen Naeem, 2017. Perilous Effects of Heavy Metals Contamination on Human Health. Pak. J. Anal. Environ. Chem. Vol. 18 ,

No.

1.http://www.ceacsu.edu.pk /PDF\%20file/Volume\%201 8\%20lssue\%201/1-17Galley\%20Proof\%20PJAE C-02032017-01.pdf. 11 Juli 2018. 